IZA DP No. 8685

Educational Attainment of Second-Generation Immigrants: A U.S.-Canada Comparison

Xingfei Liu

November 2014 


\title{
Educational Attainment of Second-Generation Immigrants: A U.S.-Canada Comparison
}

\author{
Xingfei Liu
}

$I Z A$

Discussion Paper No. 8685

November 2014

\author{
IZA \\ P.O. Box 7240 \\ 53072 Bonn \\ Germany \\ Phone: +49-228-3894-0 \\ Fax: +49-228-3894-180 \\ E-mail: iza@iza.org
}

\begin{abstract}
Any opinions expressed here are those of the author(s) and not those of IZA. Research published in this series may include views on policy, but the institute itself takes no institutional policy positions. The IZA research network is committed to the IZA Guiding Principles of Research Integrity.

The Institute for the Study of Labor (IZA) in Bonn is a local and virtual international research center and a place of communication between science, politics and business. IZA is an independent nonprofit organization supported by Deutsche Post Foundation. The center is associated with the University of Bonn and offers a stimulating research environment through its international network, workshops and conferences, data service, project support, research visits and doctoral program. IZA engages in (i) original and internationally competitive research in all fields of labor economics, (ii) development of policy concepts, and (iii) dissemination of research results and concepts to the interested public.
\end{abstract}

IZA Discussion Papers often represent preliminary work and are circulated to encourage discussion. Citation of such a paper should account for its provisional character. A revised version may be available directly from the author. 


\section{ABSTRACT \\ Educational Attainment of Second-Generation Immigrants: A U.S.-Canada Comparison}

In this paper, I analyze educational outcomes for second generation immigrants and compare them to those of natives. I use a dynamic structural model and focus on transition paths from school to work for youths in Canada and the U.S. Using data extracted from the 1997 National Longitudinal Survey of Youth and the 2000 Youth in Transition Survey, I find that family background is closely related to educational attainment of white children of immigrants in both countries. Moreover, cognitive abilities seem to be more important in determining youths' educational attainment in the U.S. than in Canada. However, I find no evidence suggesting that the effects of key family environment variables on educational attainment differ between children of immigrants and children of natives. Results from counterfactual simulations suggest that incentive-based educational reforms, such as providing educational subsidies to reduce the costs of secondary and post-secondary education, are more effective in increasing overall educational attainment for both groups. In addition, the desired dollar amount of these educational subsidies are smaller in Canada than in the U.S. On the other hand, immigration policies designed to admit only highly educated individuals have modest effects on educational attainment of second generation immigrants. Finally, there is very little difference in educational outcomes between the two groups in Canada and the U.S. despite very different immigration policies, at least for the ethnic group (whites) considered in this paper.

JEL Classification: $121, \mathrm{~J} 15, \mathrm{~J} 24$

Keywords: second-generation immigrants, educational attainment, counterfactual-simulation, dynamic structural model, U.S.-Canada comparison

Corresponding author:

Xingfei Liu

IZA

P.O. Box 7240

53072 Bonn

Germany

E-mail: liu@iza.org

\footnotetext{
* I am grateful to Jorgen Hansen, Barry R. Chiswick, Harriet O. Duleep for their useful comments and suggestions for this version of the paper. I am also grateful to comments and suggestions from participants of research seminars at RDC conference at Queens University, at Concordia University and at the CEA conferences on earlier drafts of this paper. All typos and errors are mine.
} 


\section{Introduction}

How immigrants fare in their host or destination countries has generated a huge literature in economics. Most of the work has focused on experiences in countries with relatively long histories of immigration and with highly developed economies, such as the U.S. and Canada (see Abbott and Beach 1993; Baker and Benjamin 1994; Borjas 1994, 2000; Bloom, Grenier and Gunderson 1995 and Camarota 2007). Evidence of wage gaps as well as differences in educational attainment between immigrants and the native population has been well documented in the literature (e.g. Funkhouser and Trejo 1995; Cohen, Zach and Chiswick 1997; Borjas 2000 and Frenette and Morissette 2005).

While a large economic literature exists on how immigrants integrate or assimilate, less attention has been paid to how children of immigrants fare. Since many immigrants decide to stay and raise their children in the host country, a more complete analysis of costs and benefits associated with immigration should reflect a longer-term perspective that also considers how children of immigrants succeed relative to children of natives. This is particularly true for the U.S. and Canada given their long history of receiving immigrants. Existing research (Hansen and Kucera 2004; Aydemir and Sweetman 2008; Aydemir, Chen and Corak 2008; Hansen, Liu and Kucera 2010) have shown that children of immigrants generally acquire more education than otherwise similar children of native-born parents in both Canada and the U.S. However, in Europe, the opposite appear to be true. Studies by Nielsen, Rosholm, Smith and Husted 2001; Van Ours and Veenman 2002, 2003; Riphahn 2003, 2004 and Colding, Husted and Hummelgaard 2009 show that children of immigrants are not as successful as children of natives in terms of educational attainment.

Most of previous work in this area (with the exception of Hansen, Liu and Kucera 2010) have been descriptive and therefore not been able to explain why such these educational differences exist. For example, an educational gap may arise because of differences in cognitive abilities between children of immigrants and children of natives. Furthermore, these ability differences could occur if abilities are transmitted across generations and if there is a non-random selection of immigrants where only those with high abilities find it worthwhile migrating or are the only ones accepted in the host country.

In order to advance our knowledge in this area, we need to move beyond the descriptive data analysis that is prevalent in previous studies. Specifically, there is a need to respect the structure and dynamic nature of the educational process when studying these issues. Consequently, in this paper I formulate and estimate an economic model of educational attainment of young adults who optimally choose between school and work based on their own abilities, preferences and opportunities. The behavioural parameters are estimated using data from the 1997 cohort of the National Longitudinal Survey of Youth and from the reading cohort of the Youth in Transition Survey (YITS - cohort A). The two surveys provide an excellent opportunity to conduct a comparable analysis of educational attainment of youths in the U.S. and Canada because of their detailed information on education and family background as well as the 
similarity of the surveys in terms of sample and questionaires.

In this paper, the analysis is restricted to white males. The NLSY 97 identifies three major ethnic groups; whites, blacks and hispanics. However, the sample sizes in YITS for blacks and hispanics are not sufficiently large to allow meaningful comparisons between children of immigrants and children of natives in the two countries. Descriptive statistics show that family environment is important in shaping young individuals' educational decisions regardless of their immigration status, this is true in both Canada and the U.S. In Canada, educational attainment is similar for children of immigrants and children of natives. This is not the case in the U.S. where children of immigrants acquire more schooling, on average, than children of native-born parents. Estimation results indicate that family characteristics, in particular parental education and income, have positive effects on children's schooling attendance, yet these effects are small in magnitudes. ${ }^{1}$ Moreover, in the U.S., the observed advantage in second-generation immigrants' educational attainment over children of nativeborn parents is closely related to their stronger family background. The results also suggest that there are some notable differences in preferences for schooling between the two countries. Moreover, simulation results show that youths in the U.S. are more responsive to reductions in psychic costs than are youths in Canada. In general, the simulation exercises suggest that improved family backgrounds have limited impacts on children's educational attainment in both Canada and the U.S. while incentive-based reforms, which reduce the cost of post-secondary schooling, have an effect.

Overall, I believe that the results in this paper are interesting as they reveal whether and how family background and preferences affect educational decisions in the U.S. and Canada. The rest of the paper is organized as follows. The model is introduced and explained in the next Section. Section 3 presents the data and descriptive statistics. The main results are presented and discussed in Section 4, where I also present how predictions from the model fit observed data. Section 5 provides results from counter-factual simulations based on the estimated model, while Section 6 concludes the paper.

\section{A Structural Model of School Choices}

In this section, I introduce a structural model that I will use to analyze educational choices of young individuals given their immigrant classification. The model is based on the ones used in Belzil and Hansen (2002 and 2007) and Hansen, Liu and Kucera (2011a and 2011b).

I assume that individuals decide sequentially whether to enter the labor market or to continue to accumulate years of schooling. Further, I assume they are rational, forward-looking individuals that maximize discounted expected lifetime utility over a finite time horizon set to the age of 65 (assumed to be the common retirement age). The model has one control variable, $d_{i t}$, which equals

\footnotetext{
${ }^{1}$ Simulation results based on improved family environment variables, such as parental education and income, suggest little impact on youths' educational attainment.
} 
one if an individual decides to stay in school and it equals zero if an individual decides to leave school and enter the labor market. Educational decisions are modeled as of age 16. The initial condition (the educational attainment at age $16)$ is potentially endogenous and denoted by $S_{i 0}$.

\subsection{Utility of Attending School}

Formally, in any period $t$ after age 16, the utility of attending school is represented by the following equation:

$$
U_{i t}^{h s}=\ln \left(C_{i t}^{h s}\right)=A^{h}\left(X_{i t}\right) I\left(S_{i t}=J\right)+\alpha_{0}^{k} S_{i 0}+a s^{k}+u h^{h}+\varepsilon_{i t}^{h s}
$$

where $J=4,5,6,7, \ldots$ and $i$ represents an individual, $k$ represents unobserved heterogeneity support and $h$ is an indicator variable that equals one if an individual is second-generation immigrant.

Further, $t$ represents a time period and $\ln \left(C_{i t}^{h s}\right)$ is defined as the instantaneous monetary returns of going to school (to make it comparable to the utility of working) for youth. ${ }^{2} A^{h}\left(X_{i t}\right)$ is assumed to be a linear function of $X_{i t}$ with different parameters for individuals with different immigration backgrounds. $X_{i t}$ contains time-invariant individual characteristics in period $t$, such as parent income, father's education, mother's education, test scores, and finally, immigrant status. ${ }^{3}$ These are initial endowments of each individual that remain fixed over time.

Empirically, $A^{h}\left(X_{i t}\right)$ is assumed to take the following form:

$$
\begin{gathered}
A^{h}\left(X_{i t}\right)=\left(\beta_{1}+\beta_{1 s} * \text { secgen }_{i}\right) * \text { fed } 1 i+\left(\beta_{2}+\beta_{2 s} * \text { secgen }_{i}\right) * \text { fed } 2_{i}+ \\
\left(\beta_{3}+\beta_{3 s} \text { secgen }_{i}\right) * \text { med }_{i}+\left(\beta_{4}+\beta_{4 s} * \text { secgen }_{i}\right) * \text { med } 2_{i}+ \\
\left(\beta_{5}+\beta_{5 s} * \text { secgen }_{i}\right) * P I_{i}+\beta_{6} * \text { nsib }_{i}+\beta_{7} * \text { nuclear }_{i}+ \\
\left(\beta_{8}+\beta_{8 s} * \text { secgen }_{i}\right) * \text { test }_{i}
\end{gathered}
$$

where secgen $_{i}$ is a binary variable that equals one if an individual has at least one immigrant parent. $f e d 1_{i}$ indicates if the father is a high school graduate while $f e d 2_{i}$ indicates if the father has completed schooling above high school. Hence, the reference group consists of fathers' with less than high school. med $1_{i}$ and $m e d 2_{i}$ represent mothers' education and are similarly defined. $P I_{i}$ stands for parental income for individual $i$ and $n s i b_{i}$ and $n u c l e a r_{i}$ represent number of

\footnotetext{
${ }^{2}$ one period in the model coincides with one academic year in the data

${ }^{3}$ In NLSY97, I use the average parental income over four years (1998-2001) while in YITS the only measure of parental income is available for 2000 .
} 
siblings and a nuclear family dummy, respectively. Finally, test $t_{i}$ stands for the test score of individual $i^{4}$

The term $\alpha_{0}^{k} S_{i 0}$ is included to control for possible endogeneity of initial schooling endowment at age 16. The indicator function, $I\left(S_{i t}=J\right)$ is included to reflect that the utility of attending school may vary with grade levels. ${ }^{5}$ In particular, $I\left(S_{i t}=J\right)$ equals one if individual $i$ completes grade level $j$ in period $t$, and zero otherwise. Finally, $a s^{k}$ represents unobserved, time invariant heterogeneity while $\varepsilon_{i t}^{h s}$ represents an iid normally distributed instant utility shock.

\section{$2.2 \quad$ Utility of Working}

The instantaneous utility of working is defined by the following equation:

$$
U_{i t}^{w}=\ln \left(w_{i t}\right)=\beta^{w}+\text { retedu } u^{w} * S_{i t}+\operatorname{retxp}^{w} * \operatorname{Exper}_{i t}+\operatorname{retxp}^{w 2} * \operatorname{Exper}_{i t}^{2}+\varepsilon_{i t}^{w}
$$

where reted $u^{w}$ and retxp ${ }^{w}$ represent the return to school and return to work experience, respectively. $\beta^{w}$ is the constant term in the wage equation. All the parameters in the wage equation are assumed to be common for every individual. ${ }^{6}$ Thus, the utility of working is assumed to be constant given individual's educational attainment and working experience.

\subsection{Initial Schooling}

It is reasonable to assume that the permanent personal endowments that help explain schooling decisions beyond age 16 are also instrumental in determining how much schooling one has acquired by age 16. A failure to account for this possibility could seriously bias the estimates of the structural parameters. Consequently, we choose to model initial schooling (at age 16) as an orderedchoice and let the grade probabilities depend on both observed and unobserved individual characteristics.

\subsection{Value Functions}

At the beginning of each period, individuals choose between continuing to invest in one more year of schooling $\left(d_{i t}=1\right)$ or terminating schooling investments and entering the labour market $\left(d_{i t}=0\right)$. The decision to enter the labour market is assumed to be permanent. That is, $d_{i t}=0$ implies that $d_{i j}=0$ for all

\footnotetext{
${ }^{4}$ In NLSY97, this variable refers to the residual obtained by regressing ASVAB verbal scores on educational attainment acquired at the time when the test was taken. In YITS it refers to the residual of regressing PISA verbal scores on educational attainment acquired at the time when the test was taken.

${ }^{5}$ Grade specific costs are added to reflect this feature.

${ }^{6}$ Since many respondents in both NLSY97 and YITS are still enrolled in school at the most recent survey date, I utilize data from the Canadian and U.S. Censuses to recover the wage parameters. One could also argue that young individuals make their educational decisions by observing the labor market through census.
} 
$j=t+1, \ldots, T$. The current discounted value of choosing to remain in school at the beginning of period $t$ can be expressed by the following Bellman equation:

$$
\begin{gathered}
V_{t}^{h s}\left(S_{t}, \Omega_{t}\right)=A^{h}\left(X_{i t}\right) I\left(S_{i t}=J\right)+\alpha_{0}^{k} S_{i 0}+a s^{k}+u h^{h}+\varepsilon_{t}^{h s}+ \\
\beta\left\{E M A X\left[V_{t+1}^{h s}\left(S_{t+1}, \Omega_{t+1}\right), V_{t+1}^{w}\left(S_{t+1}\right)\right]\right\}
\end{gathered}
$$

where $\beta$ is the discount factor. The state variables $S_{t}$ represent educational attainment at the beginning of period $t$, while $\Omega_{t}$ contains information on the individual's initial educational attainment $\left(S_{i 0}\right)$, personal characteristics, unobserved heterogeneity (represented by the vector $\Theta \in\left(a s^{k}, u h^{h}, \varepsilon_{t}^{h s}\right)$ ) and accumulated work experience $\left(\right.$ Exper $\left._{t}\right)$.

The value of terminating schooling and entering the labour market in period $t$ is given by:

$$
V_{t}^{w}\left(S_{t}\right)=\ln \left(w_{t}\right)+\beta E\left[V_{t+1}^{w}\left(S_{t+1}\right) \mid d_{t}=0\right]
$$

It should be noted that value function associated with working depends only on educational attainment and work experience. Furthermore, every individual share the same labour market outlook regardless of immigration status.

The second term on the right-hand side of eq.4 is simply the discounted expected value of working from period $t+1$ until retirement:

$$
\begin{gathered}
E\left[V_{t+1}^{w}\left(S_{t+1}\right) \mid d_{t}=0\right]= \\
\sum_{j=t+1}^{T} \beta^{j-(t+1)}\left\{\beta^{w}+\text { retedu }^{w} * S_{i j}+\text { retxp }^{w} * \text { Exper }_{i j}+\text { retxp }^{w 2} * \text { Exper }_{i j}^{2}\right\}
\end{gathered}
$$

Finally, each value function is solved using backwards induction and an individual chooses to terminate schooling and enter the labour market permanently in period $t$ if

$$
V_{t}^{h s}\left(S_{t}, \Omega_{t}\right) \leq V_{t}^{w}\left(S_{t}\right)
$$

\subsection{Unobserved Heterogeneity}

Unobserved heterogeneity includes any unobserved (in the data) individual characteristics, abilities and preferences that determine educational decisions. For example, unobserved heterogeneity includes taste for schooling and working, innate non-cognitive abilities, ambitions etc. Ideally, each individual should be endowed with an unique set of all these factors. However, this is not feasible when we confront our model with survey data. Instead, as is customary in these types of models, I model unobserved heterogeneity as a set of random variables that are discretely distributed. Thus, I assume that individuals can be aggregated into groups that share common characteristics, preferences and abilities. 
In particular, I assume that there are $K$ groups (or types of individuals), and express the probability of belonging to type $k$ as

$$
p_{k}=\frac{\exp \left(q_{k}\right)}{\sum_{j=1}^{K} \exp \left(q_{j}\right)}
$$

where $q_{k}=0, k=1,2, \ldots, K$. The number of types or groups $(K)$ is estimated using the Akaike Information Criteria.

\subsection{The Likelihood Function}

The dynamic programming problem is solved using backward recursion and the parameters of the model are estimated using maximum likelihood techniques. The decision rule $d_{t}, t \in\{0,1,2,3, \ldots, 11\}$, determines the transition path from school to work. Given the value functions defined above, the transitional probabilities are:

$$
\begin{aligned}
& \operatorname{Pr}\left(d_{t+1}=0 \mid d_{t}=1\right)=\operatorname{Pr}\left(V_{t+1}^{w}\left(S_{t}\right) \geq V_{t+1}^{s}\left(S_{t}\right)\right) \\
& \operatorname{Pr}\left(d_{t+1}=1 \mid d_{t}=1\right)=\operatorname{Pr}\left(V_{t+1}^{w}\left(S_{t}\right)<V_{t+1}^{s}\left(S_{t}\right)\right)
\end{aligned}
$$

These probabilities can be calculated given distributional assumptions of the time-varying utility shocks. The likelihood function, conditional on unobserved heterogeneity, consists of the following two parts:

- The probability of observing a particular sequence of schooling histories, given by

$$
L_{1}(k)=\operatorname{Pr}\left\{\left[d_{0}(k)\right],\left[d_{1}(k)\right], \ldots,\left[d_{\tau}(k)\right]\right\}
$$
by $^{7}$

- The probability of having completed $S$ years of schooling at age 16 , given

$$
L_{2}(k)=\operatorname{Pr}\left(S_{i 0}=s\right), s \in\{7,8,9,10,11, \ldots\}
$$

Hence, the complete conditional likelihood function is given by

$$
L_{i}(k)=L_{1}(k) L_{2}(k)
$$

where $L_{i}($.$) is the the likelihood contribution of individual i$, belonging to type $k$. Finally, the complete unconditional log-likelihood contribution of individual $i$ is given by

$$
\log L_{i}=\log \sum_{k=1}^{K} p_{k} L_{i}(k)
$$

where $p_{k}$ is the probability of belonging to group $k$.

\footnotetext{
${ }^{7}$ This probability is obtained by using an ordered probit model.
} 


\section{Data}

In this paper, I utilize data extracted from the 1997 cohort of the National Longitudinal Survey of Youth for the U.S. and the Reading Cohort of the Youth in Transition Survey for Canada, henceforth NLSY97 and YITS, respectively. Both surveys provide detailed information on educational achievement and socio-economic characteristics, including measures of cognitive skills. By utilizing both surveys I am able to compare how educational decisions of young individuals, including children of immigrants, were formed over the last decade in both countries. I use information from the beginning of 1997 to the end of 2007 (11 surveys) from NLSY97 and from the beginning of 1999 to the end of 2007 (5 cycles) from YITS.

In the U.S., where the 1979 cohort of the NLSY has long been a major source of information on the transition from school to work, the use of NLSY97 has until recently been limited by the young age of the respondents. Since the NLSY97 consists of youths aged 12 to 16 in 1996, a meaningful analysis of school to work transitions has only now become feasible for this cohort. Similarly, in Canada, the reading cohort of YITS consists of young individuals aged 15 in 1999 and respondents only recently started to make school to work transitions. Both NLSY97 and YITS record detailed family environment and educational information on similarly aged youth in both countries. Having access to these surveys gives me a good opportunity to look at how family environment together with cognitive skills shape young adults' educational decisions given their immigration statuses within the two neighboring countries, both with long histories of immigration.

In this study, I focus on how educational and early labour market outcomes of children of immigrants in the U.S. and Canada compare with children of U.S. and Canadian born parents. Furthermore, I want to compare educational attainment of children of immigrants between U.S. and Canada, and find out how these differences relate to their family backgrounds. In particular, an individual is defined to be second-genreation immigrant if at least one of his parents was born abroad.

Information on individual's family background is collected from both surveys. Specifically, the following variables are used: immigration status; parental educational attainment; parental income; number of siblings; and whether the child lives with both biological parents at age 14. Test scores measuring individuals' cognitive skills are also utilized. The sample sizes are 1,348 for NLSY97 and 4,731 for YITS.

\subsection{AFQT and PISA Scores}

By incorporating test scores in the model, I can examine how much of educational differences across immigrant groups are due to differences in cognitive skills. Fortunately, both the NLSY97 and YITS offer unique opportunities to control for cognitive abilities. In the NLSY97, cognitive achievements are measured by the Armed Forces Qualification Test (AFQT) scores. In particular, 
the AFQT scores were constructed from four subtests of the ASVAB. ${ }^{8}$ There is ample evidence showing that AFQT scores are closely related to educational achievement.

Information on cognitive skills in YITS are obtained from a series of standardized achievement tests taken by youths in the first wave of the survey. The tests were administered by the Programme for International Student Assessment (PISA). ${ }^{9}$ However, the AFQT measures from the NLSY97 and the PISA scores from YITS cannot be readily compared at individual levels due to the fact that different methods and aspects were utilized and assessed to generate the scores. Furthermore, the age and grade level at which individuals took these tests differ between the two surveys. In order to make the analysis more comparable across surveys, I use only Verbal scores from both surveys. ${ }^{10}$

Moreover, since test scores are utilized to control for measured scholastic abilities and test scores are closely correlated with certain level of obtained schooling, I need to purge the test scores from educational attainment. In order to avoid biased estimates of the preference parameters, I use adjusted ability measures obtained as the residuals from regressions of test scores on years of schooling at the time when individual took the test. The regression results from both surveys can be found in Table 16 in Appendix.

\subsection{School Status and Wages}

Information on school enrolment status was obtained using monthly full-time school enrolment records from both NLSY97 and YITS. ${ }^{11}$ Further, by utilizing information on monthly full-time student status and the date of birth (month), I was able to calculate accumulated grades completed for each academic year beyond age 16 .

Information on wage measures were obtained from the 2000 U.S. and Canadian Censuses. Specifically, from each Census, a sample of white males aged between 25 and 65 was collected and used for the log wage regressions. Information on reported annual earnings, hours of work during Census week, weeks worked previous year, age and educational attainment was collected. Hourly wages were derived by dividing annual earnings by annual hours of work. I removed individual observations where the hourly wage was below the federal minimum wage rate in both coutries in 1999. A proxy for work experience was obtained by subtracting years of schooling plus 6 from age. Finally, log wage regressions, which take the form of eq.2 above, were estimated and the estimates

\footnotetext{
${ }^{8}$ The Armed Services Vocational Aptitude Battery (ASVAB) contains 10 sub-tests. The four subtests included in the AFQT are Word Knowledge, Paragraph Comprehension, Arithmetic Reasoning and Numerical Operation or Numerical Comprehension.

${ }^{9}$ PISA measures 15 years old students' skills and knowledge levels at the end of their compuslsory education to assess if they are ready to participate as adults in the society. In particular, PISA measures three aspects of individual skills and knowledge: Mathematics, Sciences and Verbal.

${ }^{10}$ Another reason for only considering Verbal scores is that many youths in YITS did not complete the math test.

${ }^{11}$ Part-time students are treated as workers in this paper.
} 
were used to derive values of work, conditional on educational attainment, for each individual. All wage and income measures were adjusted to 1999 dollars. The OLS log wage regression results can be found in Table 2 .

\subsection{Descriptive Statistics}

According to my definition of second-generation immigrants, 5.6 percent of the respondents in the NLSY97 sample are children of white immigrants while the corresponding figure for the YITS sample is 10.7 percent. If visible minorities are included, the two figures are instead 12 percent for the U.S. and 15 percent for Canada. In this case, the proportion of Hispanic children of immigrants is much larger in the U.S. than in Canada. This difference reflects the fact that immigration policies in the U.S. focus on "Family Reunion" combined with the fact that there are substantially more Latin American immigrants in the U.S. than in Canada.

\subsubsection{Family Environment}

Table 1 shows descriptive statistics for key variables for both samples. Parental educational is classified into 3 categories: 1) less than high school, 2) high school graduate and 3) above high school. Both samples suggest that children of immigrants tend to have higher educated parents than children of nativeborn parents. For example, in the NLSY97, father's education is equivalent to or higher than university degree for 45 percent of children of immigrants while this figure is 28 percent for children of natives. A similar pattern is observed for mother's education. In the YITS sample, similar differences are found although the overall educational attainment among parents is lower than in the U.S.

Evidence from the two samples suggests that children of immigrants, compared to native children in both countries, tend to come from larger families and they are more likely to live with both biological parents in their teenage years.

In both the NLSY97 and YITS, parental income is generated by summing up both parents' gross incomes in 2000. This measure is then adjusted to 1999 dollars. In the U.S., average parental income for children of immigrants is around US $\$ 76,000$ (which using an exchange rate of 1 US $\$=$ CAD $\$ 1.45$ in 2000 corresponds to about CAD $\$ 110,200$ ). This is around 23 percent higher than the average parental income of children of natives (US \$61,700). In Canada, similar differences exist between children of immigrants and children of natives although the average income levels are much lower in Canada. Thus, overall these data suggest that, in 2000, white parents in the U.S. earn more than similar parents in Canada. Moreover, parents of children of immigrants earn, on average, more than parents of children of natives in both countries.

Based on data from the two samples, it appears as if children of immirants in both Canada and the U.S. have stronger family backgrounds than similar children of native-born parents at the end of the 1990s. Specifically, children of immigrants have higher parental income, better educated parents and are more 
likely to live with both biological parents when they are young. In Canada, this phenomenon could be partly explained by the implementation of an immigration policy that was introduced in 1967 and focused on bringing highly educated individuals with language and working skills to Canada.

\subsubsection{Cognitive Abilities}

Cognitive abilities were measured in both surveys before the respondents reached the age of 16. I use verbal scores from ASVAB and PISA, respectively, to represent cognitive skill measures. Specifically, ASVAB_Verbal from the NLSY97 is a percentile score that varies between 0 and 100, with a higher score implying higher ability. For YITS, I used reading scores from PISA 2000 as an ability measure. The values of this veriable range from 0.84 to 8.87 , and higher scores corresponds to better performances in the tests.

Children of immigrants in the NLSY97 have on average much higher test scores (at 67/100) than children of natives (at 57/100). In Canada, the average test scores are similar for both children of immigrants and children of natives (around 5.08).

\subsubsection{Educational Attainment}

Data from the NLSY97 suggest that children of immigrants on average accumulate more years of schooling (13.5) than children of natives (13). Moreover, there are less high school dropouts among children of immigrants (12\%) than among children of natives (19.7\%). The proportion of students attending college or university is also higher among children of immigrants. In particular, 42 percent of children of immigrants attended college or university while the corrsponding figure for children of natives is 33 percent.

A different picture emerges when looking at data from the YITS sample. There are virtually no differences in average years of schooling between the two groups (13.44 vs. 13.41). Moreover, the distribution of years of schooling is similar at each grade level for this sample (see Table 3 ).

It is important to note that there are provincal differences in the organization of education as well as in educational outcomes. For example, in the province of Quebec, students complete theor secondary education after completing grade11. If they decide to enrol in post-secondary education, they would normally attend "CEGEP" (College d'enseignement general et professional'). CEGEP is considered a college level education in Quebec and it usually takes two years to complete. After the two years, students can apply to university or complete a third year and obtain a vocational college diploma. Given that Quebec is one of the largest provinces in Canada, my sample contains a considerable number of students from this province. The most recent cycle of YITS used in this paper contains personal educational information until the end of 2007 at which time the respondents have reached the age of 23 . Given the young age of individuals in the survey, many individuals are still in school when last surveyed (including those who drop out of the survey between cycles). The overall rate of individu- 
als who are observed to have a truncated educational stream is about 9 percent for both children of immigrants and children of natives. For NLSY97, this rate is only 3 percent. This is due to the fact that respondents in this survey were older in 2007 (between 23 and 27 years old).

Based on the information in Table 3, 50.2 percent of children of natives in Canada have completed at least 13 years of education (generally beyond high school) while this number is 40.7 percent in the U.S. On the other hand, 51.7 percent of children of immigrants in Canada have finished at least 13 years of schooling while this number is 50.7 percent in the U.S. When higher education (beyond grade 13) is considered, Canadian males are doing better than American males regardless of their parental immigration status. However, native Canadian children are doing much better than their American peers in higher education (beyond grade 13).

\section{Empirical Results and Model Fit}

\subsection{Estimation Results}

The estimated model parameters are presented in Tables 4.1, 4.2 and 4.3. The parameters were obtained from models designed to control for unobserved heterogeneity.

The results suggest that grade specific utilities or (negative) costs are important in determining educational attainment for both second-generation immigrant children and native children. The magnitude for these parameters are large compared to other parameters and they are generally statistically significant. Interestingly, compared with other grade levels, the costs are smaller (implying higher utility) for grade 12 (high school equivalent) and grade 16 (4year university equivalent) for both the U.S. and Canada. This fact suggests that in both countries, individuals are trying to get through at least high school before merging into the labour market. The estimated parameters further reveal that higher grades are associated with higher costs, which is expected as post-secondary education is typically financed in part by user fees.

Estimation results based on the NLSY97 sample suggest that family background variables are closely related to educational attainment of the child. Higher parental educational attainment imply higher utility of attending school for the child and help the child to stay in school longer. The same relationship is observed for family income. Furthermore, fewer siblings and living with both biological parents both increase the utility of school. As expected, cognitive abilities play a significant role in increasing individuals' utility of school. More importantly, no evidence were found to claim that these family environment variables together with test scores would affect children of immigrants differently. So the higher educational attainment of children of immigrants in the U.S. is mainly explained by their much stronger family background as well as by their better performances in cognitive skill tests.

Results derived from the Canadian sample convey a similar message. Most of 
the parameters show expected signs (better family background helps to increase the utility of school) and the tie between educational attainment and family environment is strong. For example, improved parental education benefit both children of immigrants and children of natives. However, unlike the U.S. results, number of siblings has no significant effect on the utility of school. Interestingly, the effect of mother's education is larger for children of immigrants than for children of natives. The results show that, in general, young adults' educational decisions in Canada are closely related to their family background. Finally, in Canada, reading test scores do not play a significant role in determining the utility of school.

\subsection{Model Fit}

After recovering the parameters in the empirical model, I generate simulated educational outcomes based on the parameters. Specifically, Table 5 shows both observed and simulated grade distributions from both samples. The generated educational outcomes are similar to those observed in the data. It is encouraging to see that the structural dynamic model has the ability to closely fit the data. In the next section, outcomes from several counter-factual simulations of the model are presented in order to illustrate how students are expected to react to alternative changes in characteristics and environment.

\section{Simulations}

Interpreting estimates from structural models is challenging given the usually complex features accompanied with these models. Consequently, it is not straightforward to interpret the magnitude of the estimated parameters from the current model. Instead, simulations are important tools that can be used to understand how outcomes change when parameters or observable characteristics change. For example, the current model can be used to generate counter-factual outcomes when parental educational attainment is modified for some or all respondents. The benefits of estimating a relatively complex dynamic structural model such as the one used in this paper is that it provides us with a unique opportunity to forecast individual behaviour under certain policy changes or reforms.

The credibility of the simulated outcomes depends on whether the model can accurately specify the decision making process of the individuals. A few recent studies have focused on establishing the validity of structural models. Typically, structural models are validated by comparing predicted outcomes from the model with those observed in the data (like Section 4.2 in this paper). However, even if the model passes this "internal" model fit criteria, it may not be suitable for predicting outcomes from counter-factual policy environments. Keane and Wolpin (2007) shows that a carefully designed structural model can indeed be used to provide information on individual reactions to policy changes. Other studies that validate structural models include Todd and Wolpin (2006) 
and Hansen and Liu (2011).

In line with the model assumptions, I assume that the recovered parameters represent individuals' preferences over education. Hence, the reference group is defined as educational outcomes derived from the model described in Section 2. I will then conduct six alternative simulations using the estimated model and compare the simulated outcomes to those of the reference group.

The first four simulations are carried out by increasing parental education and parental income. Specifically, the idea is to increase parental education for each individual and see how individuals (especially second-generation immigrants) are expected to react. Since parental education and parental income are closely correlated, it is also reasonable to increase parental income together with parental education. To capture the relationship between parental education and income, I regress parental income on parental education and the second-generation immigrant dummy. I then use the OLS estimates to adjust income levels when parental education is increased to a certain level. The OLS results can be found in Table 6 .

In particular, I first increase educational attainment of fathers (mothers) who have less than high school so that all fathers (mothers) are at least high school graduates. I then in a seperate simulation, increase both parents' education in this fashion. In the fourth simulation, I increase eductaional attainment of both parents who had a high school diploma or less. In Table 7, I report changes in average educational attainment for both children of immigrants and children of natives as a result of these counterfactual simulations. In the first three simulations, where parental education is only increased if they have less than a high school diploma, the impacts on childrens education are very small. In particular, no effects are found for children of immigrants in the U.S. sample and only simulations 2 and 3 generate (modest) improvements for children of immigrants in Canadian sample. This finding is mainly driven by the fact that very few second-generation immigrants in both samples have parental education that is lower than high school. The results for children of natives are similar to those for children of immigrants in both countries. The outcomes of the fourth simulation suggest that if parental education is increased to levels above high school, educational attainment is predicted to increase by one to two percent. Children of immigrants appear to benefit more from improved parental education than children of natives, both in Canada and in the U.S.

The next two simulations are designed to evaluate the amount of educational subsidies needed to put an individual through high school and university, respectively. In particular, the mechanism of the dynamic educational choice model is to compare an individual's life-time utility of working conditional on his educational level and his utility of school, obtained by staying in school for an additional year. Individuals stay in school because the utility of school exceeds utility of working (high educational attainment possibly entails higher wages in the future). On the contrary, if individuals decide to leave school for work, according to the model, it must imply that utility of earning wages at current educational level exceeds utility of having one more year of education and possibly enjoying higher wages in the future. With the help of the estimated 
model parameters, I am able to find out the differences between utility of school and utility of work at different grade levels conditional on individual's personal characteristic. These differences can, in turn, be used to infer the range of educational subsidies that would be required to; i) ensure that everyone completes high school and ii) ensure that those who attend post-secondary education also complete their degree.

Specifically, I identify individuals who would potentially drop out of high school, predicted by my model, and increase their utility of school at each level of education at and below grade 12. The amount of subsidy for each year equals the difference between the value of work and the value of school whenever the value of work is larger and zero otherwise. These differences are then transformed into equivalent annual dollar amount. ${ }^{12}$ Similarly, based on the model, for individuals who would obtain high school diploma (grade=12) but have not finished university (grade $<16$ ), I also calculated the subsidy amounts at grades $13,14,15$ and 16 needed for these individuals to graduate from university (grade $16)$.

Simulated subsidy levels are reported in Table 13.1 and Table 13.2. The required subsidies are generally larger in the U.S. than in Canada. This is true for both children of natives and children of immigrants. It is also true for both the high school completion subsidy and the university graduation subsidy. ${ }^{13} \mathrm{Al}-$ though average annual subsibies are slightly lower for second generation white immigrants than for native Whites in both countries and at both levels, there is no statistical evidence to show that this difference was driven by the immigration status. ${ }^{14}$ Interestingly, regressions of high school subsidies on individuals' family environment variables suggest that there is virtually no effect of family background on the level of high school subsidy in Canada. However, this is not the case in the U.S. where cognitive ability does have a significant negative effect on the level of high school subsidy.

Similarly, regression results based on university level subsidies suggest that in Canada, only father's education (more than high school) will reduce the subsidy amount for children of immigrants. In the U.S., the correlation between family background and university subsidy amounts is higher. It also suggests that father's education, test scores, and living with both parents are factors that can effectively reduce the level of subsidy for children of immigrants in the U.S. ${ }^{15}$

One should be careful when interpreting the dollar amount of subsidies calculated using the model estimates in this environment. The difference between utility of school and utility of work may include many factors. It may contain actual educational cost at different educational levels but it may also contain

\footnotetext{
${ }^{12} \log$ of hourly wages were compared with utility of school in the estimation process, so I calculated the annual dollar amount of subsidy by multiply the exponential of the utility difference by 2000, assuming that annual total hours of working on a full-time basis is 2000 .

${ }^{13}$ Subsidy amounts were not PPP adjusted, but average exchange rate between U.S. Dollar and Canadian Dollars in 2000 was about $1.45 \mathrm{CAD}=1 \mathrm{USD}$.

${ }^{14}$ Regression of subsidies on the second-generation immigrant dummy in both countries yield non-significant coefficients and virtually zero $R^{2}$.

${ }^{15}$ These regression results are available upon request.
} 
psychic cost occured to individuals who would need compensation to stay longer in school. It may also contain any other unobserved cost or disutility of attending school. The estimated annual dollar amounts needed to move individuals beyond certain levels of education (high school or university) will potentially incorporate all possible "costs" faced by decision-making young individuals.

\section{Conclusion}

In this paper, I formulate a dynamic structural model to compare educational attainment of children of immigrants in the U.S. and Canada. Among other things, I analyze to what extent parental eduction affect educational decisions of children of immigrants in the two countries.

Two samples of young white males were collected from the NLSY97 and YITS, respectively. Descriptive statistics based on the two samples suggest that children of immigrants tend to have stronger family backgrounds than children of natives in both countries. Compared to native children, children of immigrants have better educated parents.

Based on the U.S. sample, children of immigrants have higher educational attainment than children of natives. They are more likely to attend post-secondary education, and less likely to drop out of high school. Compared to native children, they also perform better on standardized tests designed to measure cognitive skills. On the other hand, children of immigrants in Canada have generally the same educational attainment as children of native Canadians and there are no differences in test scores between the two groups.

A dynamic structural model of school choices is employed in this study to analyze how family environment and test scores affect youths' educational decisions. Estimated parameters of the model suggest that, in the U.S., family background is closely related to educational attainment. Better family environment implies higher educational attainment of the child. Moreover, the results suggest that the educational differences between the two groups in the U.S. are mainly due to differences in family background and test scores rather than differences in preferences towards education. Similar results apply for Canada where the estimated parameters of the model also indicate that family environment is closely related to the educational attainment of the child.

Simulation results suggest that increasing parental educational attainment and parental income have limited positive effects on educational attainment of children of immigrants and natives, both in the U.S. and in Canada. On the other hand, incentive based policy changes such as reducing educational costs can generate relatively large positive effects on educational attainment of youths regardless of their immigration status. Moreover, the required subsidy amounts are larger in the U.S. than in Canada which may imply that costs play a more important role in the U.S. than in Canada.

To attract highly educated and motivated new workers has been an important emphasis in Canadian immigration policy since the 1960s. As shown in this study, although restricted to white males only, children of immigrants have 
stronger parents in terms of educational attainment and income. Further, for this ethnic group, second-generation immigrants are doing well in both countries in terms of educational attainment. In fact, average education is slightly higher for second-generation immigrants in both countries. Thus, for whites, there is very little difference in educational outcomes between the two groups in Canada and the U.S., despite very different immigration policies. It should be noted that the results in this paper are restricted to whites and the analysis ignores outcomes among other ethnicities, such as blacks and hispanics. It is possible that differences between second-generation immigrants and natives in school outcomes are larger for these groups and also that there exists country differences as well.

\section{References}

[1] Abbott, M. and C.M. Beach, 1993 "Immigrant Earnings Differentials and Birth Year Effects for Men in Canada: Post-1972." Canadian Journal of Economics 25: 505-24.

[2] Aydemir, A. and A. Sweetman, 2008, "First and Second Generation Immigration Educational Attainment and Labor Market Outcomes: A Comparison on the United States and Canada," Research in Labor Economics 27: 215-70.

[3] Aydemir, A., W.H. Chen, and M. Corak, 2008, "Intergeneration Educational Mobility among the Children of Canadian Immigrants," Analytical Studies Branch Research Paper Series, 316, F0019M. Ottawa: Statistics Canada.

[4] Baker, M. and D. Benjamin, 1994, "The Performance of Immigrants in the Canadian Labor Market ," Journal of Labor Economics 12: 369-405.

[5] Belly, P., M. Frenette, and L. Lochner, 2010, "Post-Secondary Attendence by Parental Income: Comparing the U.S. and Canada," Working Paper, University of Western Ontario, London, Ontario, Canada.

[6] Belzil, C. and J. Hansen, 2002, "Unobserved Ability and the Return to Schooling," Econometrica, 70(5): 2075-2091.

[7] Belzil, C. and J. Hansen, 2007, "A structural analysis of the correlated random coefficient wage regression model," Journal of Econometrics, 140(2): $827-848$.

[8] Bloom, D.E., G. Grenier, and M. Gunderson, 1995, "The Changing Labor Market Position of Canadian Immigrants," Canadian Journal of Economics 28: $987-1005$.

[9] Borjas, G.J., 1994, "The Economics of Immigration," Journal of Economic Literature XXXII: 1667-1717. 
[10] Borjas, G.J., 2000, $<<$ Issues in the Economics of immigration $>>$ University of Chicago Press, ISBN 0-226-06631-2.

[11] Camarota, S.A., 2007, "Immigrants in the United States 2007A Profile of America's Foreign-Born Population," Center for Immigration Studies, 1522 K Street, NW, Suite 820 Washington, DC, U.S.A.

[12] Cohen,Y., T. Zach and B. R. Chiswick, 1997, "The Educational Attainment of Immigrants: Changes over Time," Quarterly Review of Economics and Finance 37: 229-243.

[13] Colding, B., L. Husted, and H. Hummelgaard, 2009, "Educational Progression of Second Generation Immigrants and Immigrant Children" Economics of Education Review 28: 434-443.

[14] Finnie, R. and R.E. Mueller, 2009, "They Came, They Saw, They Enrolled: Access to Post-Secondary Education by Children of Canadian Immigrants," A MESA Project Research Paper, Toronto, Educational Policy Institute.

[15] Frenette, M. and R. Morissette, 2005, "Will They Ever Converge? Earnings of Immigrant and Canadian-born Workings over the Last Two Decades," International Migration Review 39: 228-58.

[16] Funkhouser,E. and S. J. Trejo, 1995, "The labor market skills of recent male immigrants: Evidence from the Current Population Survey," Industrial and Labor Relations Review, ILR Review, ILR School, Cornell University, 48(4): 792-811.

[17] Hansen, J. and M. Kucera, 2004, "The Educational Attainment of Second Generation Immigrants in Canada: Evidence from SLID," Mimeo.

[18] Hansen, J., X.F. Liu and M. Kucera, 2011a, "Educational Attainment of Children of Immigrants: Evidence from Two Cohorts of American Youths," Working Paper, Concordia University, Montreal, Canada.

[19] Hansen, J., X.F. Liu and M. Kucera, 2011b, " Dsparities in Schooling Choices and Wages Between Ethnic Minorities and Whites: Evidence from the NLSY97," Working Paper, Concordia University, Montreal, Canada.

[20] Hansen, J. and X.F. Liu, 2011, "Estimating Labor Supply Responses and Welfare Participation: Using a Natural Experiment to Validate a Structural Labor Supply Model," IZA working paper, No.5718.

[21] Keane, M. and K. Wolpin, 2007, "Exploring the Usefulness of A Nonrandom Holdout Sample for Model Validation: Welfare Effects on Female Behaviour," International Economic Review, 48(4): 1351-1378.

[22] Nielsen, H.S., M. Rosholm, N. Smith, and L. Husted. 2001, "Intergenerational Transmissions and the School-to-Work Transition of 2nd Generation Immigrants," IZA Discussion Paper Series 296. 
[23] Todd, P. and Wolpin, K., 2006, "Assessing the Impact of a School Subsidy Program in Mexico: Using a Social Experiment to Validate a Dynamic Behavioral Model of Child Schooling and Fertility," American Economic Review, 96(5): 1384-1417.

[24] Van Ours, J. and J. Veenman, 2002, "From Parent to Child; Early Labor Market Experiences of Second-Generation Immigrants in the Netherlands," IZA Discussion Paper Series 649.

[25] Van Ours. J. and J. Veenman, 2003, "The Educational Attainment of Second-Generation Immigrants in the Netherlands," Journal of Population Economics, 16(4): 739-753.

[26] Riphahn, R. T., 2003, "Cohort Effects in the Educational Attainment of Second Generation Immigrants in Germany: An Analysis of Census Data," Journal of Population Economics, 16(4): 711-737.

[27] Riphahn, R. T., 2004, "Are there Diverging Time Trends in the Educational Attainment of Nationals and Second Generation Immigrants?" Working Paper, University of Basel, IZA, DIW. 


\section{Appendix}

Table 1

Mean Statistcs of Family Background Variables

\begin{tabular}{lcc|cc} 
& \multicolumn{2}{c}{ NLSY9 } & \multicolumn{2}{c}{ YITS (Reading Cohort) } \\
Variable & Secgen & Native & \multicolumn{1}{c}{ Secgen } & Native \\
\hline$S_{i 0}$ & 9.63 & 9.41 & 10.34 & 10.26 \\
nsib & 2.35 & 2.29 & 1.44 & 1.40 \\
nuclear & 0.81 & 0.68 & 0.91 & 0.86 \\
$P I$ & 76.45 & 61.70 & 77.45 & 67.30 \\
$P I S A-V$ & - & - & 5.09 & 5.08 \\
ASV $A B-V$ & 67.51 & 57.22 & - & - \\
fed & 0.11 & 0.13 & 0.11 & 0.20 \\
fed $_{1}$ & 0.21 & 0.37 & 0.20 & 0.24 \\
fed $_{2}$ & 0.68 & 0.50 & 0.69 & 0.56 \\
& & & &
\end{tabular}

Note:

$S_{i 0}$ : initial educational attainment upon age 16 .

nsib: number of siblings in the household at age 16 .

nuclear: indicator of whether live with both parents before age 16 .

$P I$ : parental income in ten thousands dollars.

$P I S A-V:$ PISA verbal test score.

$A S V A B-V:$ ASVAB verbal score.

$f_{e} d_{0}$ : father's education less than highschool.

$f e d_{1}$ : father's education highschool only.

$\mathrm{fed}_{2}$ : father's education higher than highschool. 
Table 1

\section{Mean Statistcs of Family Background Variables}

\section{(Continued)}

\begin{tabular}{lcc|cc} 
& \multicolumn{2}{c}{ NLSY97 } & \multicolumn{2}{c}{ YITS } \\
Vriable & Secgen & Native & Secgen & Native \\
\hline med $_{0}$ & 0.01 & 0.10 & 0.08 & 0.13 \\
med $_{1}$ & 0.25 & 0.37 & 0.24 & 0.30 \\
med $_{2}$ & 0.73 & 0.53 & 0.68 & 0.57 \\
acedu & 13.53 & 13.00 & 13.44 & 13.41 \\
secgen & \multicolumn{2}{c}{0.0556} & & 0.1076 \\
\hline
\end{tabular}

Note:

med $_{0}$ : mother's education less than highschool. med $_{1}$ : mother's education highschool only. $\operatorname{med}_{2}$ : mother's education higher than highschool.

acedu: accumulated education in the last observed survey year. secgen: second-generation immigrant dummy. Secgen: Individuals with at least one immigrant parent Native: Individuals with both parents non-immigrants 
Table 2

OLS log Wage Regression Results from the Censuses

\begin{tabular}{|c|c|c|}
\hline Parameter & $\begin{array}{l}\text { U.S. Census } 2000 \\
\text { Estimates (st.err) }\end{array}$ & $\begin{array}{c}\text { Canadian Census } 2000 \\
\text { Estimates(st.err) }\end{array}$ \\
\hline $\begin{array}{l}\beta^{w} \\
\operatorname{retedu}^{w} \\
\operatorname{retxp} \\
\text { retxp } \\
\text { Adjusted } R^{2}\end{array}$ & $\begin{array}{c}1.229^{* * *}(0.006) \\
0.085^{* * *}(0.0003) \\
0.028^{* * *}(0.0003) \\
-0.0004^{* * *}(0.000006) \\
0.1775\end{array}$ & $\begin{array}{c}1.711^{* * *}(0.010) \\
0.058^{* * *}(0.0005) \\
0.031^{* * *}(0.0005) \\
-0.0004^{* * *}(0.00001) \\
0.1118\end{array}$ \\
\hline \multicolumn{3}{|c|}{ 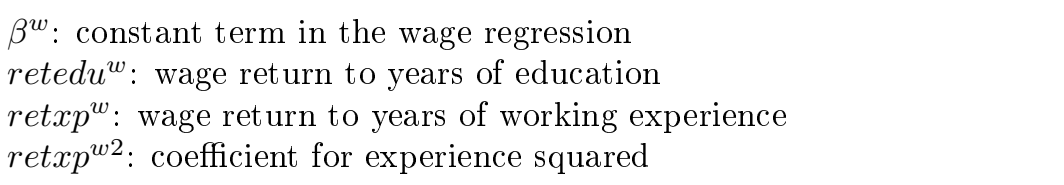 } \\
\hline
\end{tabular}


Table 3

Observed Grade Distributions (percentage) in the Last Observed Survey Year

\begin{tabular}{lcc|cc} 
& \multicolumn{2}{c}{ NLSY97 } & \multicolumn{2}{c}{ YITS } \\
Grades & Secgen & Native & Secgen & Native \\
\hline 6 & 0 & 0.08 & 0 & 0 \\
7 & 0 & 0.08 & 0 & 0 \\
8 & 0 & 1.57 & 0 & 0 \\
9 & 1.33 & 5.03 & 0 & 0.12 \\
10 & 4.00 & 5.58 & 3.73 & 3.72 \\
11 & 6.67 & 7.38 & 17.09 & 15.40 \\
12 & 37.33 & 39.59 & 27.50 & 30.60 \\
13 & 9.33 & 8.01 & 14.15 & 13.05 \\
14 & 5.33 & 4.48 & 5.11 & 6.66 \\
15 & 6.67 & 4.56 & 8.25 & 6.75 \\
16 & 16.00 & 13.20 & 9.82 & 8.36 \\
17 & 12.00 & 6.44 & 5.70 & 7.53 \\
18 & 1.33 & 2.91 & 8.45 & 7.79 \\
19 & 0 & 0.86 & 0.2 & 0.02 \\
20 & 0 & 0.16 & 0 & 0 \\
21 & 0 & 0.08 & & \\
\hline
\end{tabular}


Table 4.1

Estimated Parameters of the 2-Type Model

\begin{tabular}{lcccccc} 
& \multicolumn{3}{c}{ NLSY97 } & \multicolumn{3}{c}{ YITS } \\
Parameters & Estimates & Std Error & \multicolumn{1}{c}{ T-Stat } & \multicolumn{1}{c}{ Estimates } & Std Error & T-Stat \\
\hline Grade Specific Utilities & & & & & & - \\
Grd9 & -3.67 & 3.82 & -0.96 & - & - & - \\
Grd10 & $-7.65^{* * *}$ & 1.88 & -4.07 & - & - & - \\
Grd11 & -1.03 & 1.13 & -0.91 & $-4.89^{* * *}$ & 1.39 & -3.52 \\
Grd12 & $6.10^{* * *}$ & 0.92 & 6.61 & 0.69 & 0.49 & 1.41 \\
Grd13 & $-12.46^{* * *}$ & 0.81 & -15.34 & $-8.68^{* * *}$ & 0.40 & -21.67 \\
Grd14 & $-6.17^{* * *}$ & 1.00 & -6.15 & $-6.92^{* * *}$ & 0.44 & -15.66 \\
Grd15 & $-3.28^{* * *}$ & 1.09 & -3.01 & $-2.96^{* * *}$ & 0.49 & -6.02 \\
Grd16 & 1.17 & 1.06 & 1.11 & $-2.89^{* * *}$ & 0.50 & -5.75 \\
Grd17 & $-10.23^{* * *}$ & 1.07 & -9.52 & $-5.83^{* * *}$ & 0.54 & -10.80 \\
Grd18 & $-11.68^{* * *}$ & 1.67 & -7.00 & $-8.89^{* * *}$ & 0.68 & -13.00 \\
\hline Nrd19 & $-16.79^{* * *}$ & 2.55 & -6.59 & - & - & - \\
\hline
\end{tabular}

Grd9-Grd19: denote grade specific cost/utility (psychic educational cost) parameters in the dynamic programming model

*** significant at $1 \%$ level; ${ }^{* *}$ significant at $5 \%$ level; ${ }^{*}$ significant at $10 \%$ level 
Table 4.2

Estimated Parameters of the 2-Type Model

\section{Utility of School}

\begin{tabular}{lccc|ccc} 
& \multicolumn{3}{c}{ NLSY97 } & \multicolumn{3}{c}{ YITS } \\
Parameters & Estimates & Std Err & T-Stat & Estimates & Std Err & T-Stat \\
\hline Utility of School & & & & & & \\
$\alpha_{0}^{1}$ & 1.74 & 2.47 & 0.70 & 0.27 & 0.23 & 1.20 \\
$\alpha_{0}^{2}$ & 0.26 & 0.20 & 1.29 & 1.47 & 1.90 & 0.77 \\
$a s^{1}$ & -19.81 & 27.04 & -0.73 & 2.70 & 2.52 & 1.07 \\
$a s^{2}$ & $-4.05^{*}$ & 2.10 & -1.93 & -14.35 & 19.06 & -0.75 \\
$u h^{h}$ & -0.12 & 4.13 & 0.03 & -0.61 & 0.76 & -0.80 \\
$\beta_{1}$ & 0.28 & 0.37 & 0.75 & 0.12 & 0.18 & 0.68 \\
$\beta_{1 s}$ & -0.80 & 1.89 & -0.42 & -0.12 & 0.68 & -0.18 \\
$\beta_{2}$ & $1.42^{* * *}$ & 0.39 & 3.67 & $0.31^{*}$ & 0.16 & 1.89 \\
$\beta_{2 s}$ & $-0.66^{*}$ & 1.75 & -0.37 & -0.05 & 0.63 & -0.07 \\
$\beta_{3}$ & $1.21^{* * *}$ & 0.43 & 2.83 & 0.24 & 0.20 & 1.18 \\
$\beta_{3 s}$ & 0.50 & 4.43 & 0.11 & 0.58 & 0.77 & 0.75 \\
$\beta_{4}$ & $1.33^{* * *}$ & 0.44 & 3.02 & $0.42^{* *}$ & 0.19 & 2.14 \\
$\beta_{4 s}$ & 0.50 & 4.43 & 0.11 & 1.10 & 0.75 & 1.45 \\
& & & & & & \\
\hline
\end{tabular}

Note:

For parameter details, please refer to the model section 2.1

$\alpha_{0}^{1}$ and $\alpha_{0}^{2}$ : capture type specific effects of initial schooling on utility of school. $\beta_{1}$ and $\beta_{1 s}$ : capture the effect of having father's education at the level of high school for both native children $\left(\beta_{1}\right)$ and children of immigrants $\left(\beta_{1 s}\right)$.

$\beta_{2}$ and $\beta_{2 s}$ : capture the effect of having father's education higher than high school for both native children $\left(\beta_{2}\right)$ and children of immigrants $\left(\beta_{2 s}\right)$.

$\beta_{3}$ and $\beta_{3 s}$ : capture the effect of having mother's education at the level of high school for both native children $\left(\beta_{3}\right)$ and children of immigrants $\left(\beta_{3 s}\right)$.

$\beta_{4}$ and $\beta_{4 s}$ : capture the effect of having mother's education higher than high school for both native children $\left(\beta_{4}\right)$ and children of immigrants $\left(\beta_{4 s}\right)$.

significant at $1 \%$ level; ${ }^{* *}$ significant at $5 \%$ level; ${ }^{*}$ significant at $10 \%$ level 
Table 4.2

\title{
Estimated Parameters of the 2-Type Model
}

\author{
Utility of School
}

(Continued)

\begin{tabular}{lccc|ccc} 
& \multicolumn{3}{c}{ NLSY97 } & \multicolumn{3}{c}{ YITS } \\
Parameters & Estimates & Std Err & T-Stat & Estimates & Std Err & T-Stat \\
\hline Utility of School & & & & & & \\
$\beta_{5}$ & $0.91^{* * *}$ & 0.22 & 4.07 & $0.04^{* *}$ & 0.02 & 2.41 \\
$\beta_{5 s}$ & 0.19 & 0.72 & 0.26 & -0.04 & 0.05 & -0.83 \\
$\beta_{6}$ & $-0.22^{* * *}$ & 0.10 & -2.91 & -0.02 & 0.06 & -0.36 \\
$\beta_{7}$ & $0.86^{* * *}$ & 0.23 & 3.75 & $0.33^{* *}$ & 0.16 & 2.06 \\
$\beta_{8}$ & $0.39^{* * *}$ & 0.04 & 9.08 & $-0.13^{*}$ & 0.07 & -1.93 \\
$\beta_{8 s}$ & 0.12 & 0.19 & 0.64 & 0.19 & 0.18 & 1.08 \\
& & & & & & \\
\hline
\end{tabular}

Note:

$\beta_{5}$ and $\beta_{5 s}$ : capture efftect of parental income on utility of school for both children of natives $\left(\beta_{5}\right)$ and children of immigrants $\left(\beta_{5 s}\right)$.

$\beta_{6}$ : capture the effect of number of siblings on utility of school, which is assumed to be common for both children of natives and children of immigrants.

$\beta_{7}$ : capture the effect of nuclear family on utility of school, which is assumed to be common for both children of natives and children of immigrants.

$\beta_{8}$ and $\beta_{8 s}$ : capture efftect of cognitive skill on utility of school for both children of natives $\left(\beta_{5}\right)$ and children of immigrants $\left(\beta_{5 s}\right)$.

${ }^{* * *}$ significant at $1 \%$ level; ${ }^{* *}$ significant at $5 \%$ level $;^{*}$ significant at $10 \%$ level 
Table 4.3

\section{Estimated Parameters of the 2-Type Model}

\section{Initial Education-Ordered Probit Estimates}

\begin{tabular}{lccc|ccc} 
& \multicolumn{3}{c}{ NLSY97 } & \multicolumn{2}{c}{ YITS } \\
Parameters & Estimates & Std Err & T-Stat & Estimates & Std Err & T-Stat \\
\hline Ordered Probit & & & & & & 0.04 \\
st - fed - hs & $3.05^{* * *}$ & 1.07 & 2.85 & 0.038 & 0.97 & -0.77 \\
st - fed - hs - above & $3.22^{* * *}$ & 1.15 & 2.81 & -0.69 & 0.89 & -1.72 \\
st - med - hs & 0.76 & 1.20 & 0.64 & $-2.01^{*}$ & 1.17 & -1.82 \\
st - med - hs - above & 0.99 & 1.25 & 0.79 & $-2.09^{*}$ & 1.15 & 0.90 \\
st - PI & 0.73 & 0.77 & 0.95 & 0.09 & 0.10 & 4.83 \\
st - test & $1.00^{* * *}$ & 0.13 & 7.75 & $4.90^{* * *}$ & 1.01 & -0.51 \\
st - nsib & -0.17 & 0.32 & -0.55 & -0.16 & 0.32 & -1.45 \\
st_nuclear & $1.76^{* *}$ & 0.73 & 2.41 & -1.39 & 0.96 & 2.53 \\
st-secgen & $4.14^{* * *}$ & 1.50 & 2.75 & $3.01^{* *}$ & 1.19 & \\
& & & & & & \\
\hline
\end{tabular}

Note:

$s t-f e d-h s:$ captures the effect of father's education at highschool on individual's eduacation at age 16.

$s t-f e d-h s-a b o v e:$ captures the effect of father's education higher than highschool on individual's eduacation at age 16 .

$s t-$ med $-h s$ : captures the effect of mother's education at highschool on individual's eduacation at age 16 .

st - med - hs - above : captures the effect of mother's education higher than highschool on individual's eduacation at age 16 .

st - PI : captures the effect of parental income on individual's eduacation at age 16 .

st - test : captures the effect of cognitive skill on individual's eduacation at age 16 .

$s t-n s i b$ : captures the effect of number of siblings on individual's eduacation at age 16 .

st-nuclear : captures the effect of nuclear family on individual's eduacation at age 16 .

st - secgen : captures the effect of being a second-generation immigrant on individual's

eduacation at age 16 .

*** significant at $1 \%$ level;** significant at $5 \%$ level; ${ }^{*}$ significant at $10 \%$ level 
Table 4.3

Estimated Parameters of the 2-Type Model

Initial Education-Ordered Probit Estimates

(Continued)

\begin{tabular}{lccc|ccc} 
& \multicolumn{3}{c}{ NLSY97 } & \multicolumn{3}{c}{ YITS } \\
Parameters & Estimates & Std Err & T-Stat & Estimates & Std Err & T-Stat \\
\hline Ordered Probit & & & & & & \\
stu $1-1$ & -4.37 & 26.24 & -0.17 & $-1.37^{* * *}$ & 0.28 & -4.84 \\
stu $1-2$ & $-2.03^{* * *}$ & 0.18 & -11.37 & $-2.28^{* * *}$ & 0.82 & -2.79 \\
stu $2-1$ & -0.53 & 1.86 & -0.28 & $-1.56^{* * *}$ & 0.36 & -4.26 \\
stu $2-2$ & $-1.12^{* * *}$ & 0.15 & -7.20 & $2.34^{* * *}$ & 0.68 & 3.44 \\
stu $3-1$ & -4.84 & 22.52 & -0.21 & - & - & - \\
stu $3-2$ & $0.54^{* * *}$ & 0.15 & 3.60 & - & - & - \\
stu $4-1$ & -4.09 & 26.18 & -0.16 & - & - & - \\
stu $4-2$ & 6.34 & 53.71 & 0.12 & - & - & - \\
$q 1$ & $-4.79^{* * *}$ & 0.30 & -15.84 & $-0.41^{* * *}$ & 0.12 & -3.4 \\
pr 1 & $1 \%$ & - & - & $40 \%$ & & \\
pr 2 & $99 \%$ & - & - & $60 \%$ & & \\
& & & & & &
\end{tabular}

Note:

stu 1 - 1 up to stu4 - 2 : capture the supports of ordered probit model. $q 1$ : help to identify the probability of belonging to a specific type. $p r 1$ and $p r 2$ : denote the probabilities of belonging to certain type.

*** significant at $1 \%$ level; ${ }^{* *}$ significant at $5 \%$ level; ${ }^{*}$ significant at $10 \%$ level 
Table 5

Model Fit

Grade Distributions (in percentage) Generated from the Preferred 2-Type Model

\begin{tabular}{lcc|cc} 
& \multicolumn{2}{c}{ NLSY97 } & \multicolumn{2}{c}{ YITS } \\
Grade Levels & Observed & Model & Observed & Model \\
\hline 6 & 0.07 & 0 & 0 & 0 \\
7 & 0.07 & 0.37 & 0 & 0 \\
8 & 1.48 & 2.00 & 0 & 0 \\
9 & 4.82 & 7.05 & 0.11 & 0.23 \\
10 & 5.49 & 6.53 & 3.72 & 3.91 \\
11 & 7.34 & 7.86 & 15.58 & 14.01 \\
12 & 39.47 & 42.95 & 30.27 & 32.64 \\
13 & 8.09 & 8.46 & 13.17 & 13.30 \\
14 & 4.53 & 4.08 & 6.49 & 5.90 \\
15 & 4.67 & 3.56 & 6.91 & 6.66 \\
16 & 13.35 & 10.68 & 8.52 & 8.29 \\
17 & 6.75 & 4.15 & 7.33 & 7.08 \\
18 & 2.82 & 1.04 & 7.86 & 2.87 \\
19 & 0.82 & 0.30 & 0.04 & 3.91 \\
20 & 0.15 & 0.22 & 0 & 1.20 \\
21 & 0.07 & 0.74 & 0 & 0 \\
22 & 0 & 0 & 0 & 0 \\
Mean Accumulated Education & 13.03 & 12.56 & 13.42 & 13.45 \\
\hline
\end{tabular}


Table 6

OLS Regression Results: Parental Income and Parental Education

\begin{tabular}{lccc|ccc} 
& \multicolumn{3}{c}{ NLSY97 } & \multicolumn{3}{c}{ YITS } \\
Parameters & Estimates & Std Err & T-Stat & Estimates & Std Err & T-Stat \\
\hline & & & & & & \\
Intercept & $27.66^{* * *}$ & 4.45 & 6.21 & $40.46^{* * *}$ & 1.48 & 27.40 \\
fed - hs & $7.31^{*}$ & 4.08 & 1.79 & $9.25^{* * *}$ & 1.48 & 6.24 \\
fed - hs - above & $25.98^{* * *}$ & 4.17 & 6.23 & $18.17^{* * *}$ & 1.33 & 13.62 \\
med - hs & $11.06^{* *}$ & 4.60 & 2.40 & $9.86^{* * *}$ & 1.63 & 6.04 \\
med - hs - above & $26.68^{* * *}$ & 4.71 & 5.66 & $19.98^{* * *}$ & 1.55 & 12.70 \\
secgen & 7.20 & 5.24 & 1.37 & $6.56^{* * *}$ & 1.51 & 4.34 \\
& & & & & & \\
adjusted $R^{2}$ & & 0.13 & & & 134.57 & \\
$F-$ Stats & & 41.04 & & & 68.39 & \\
Dependent Mean & & & & & &
\end{tabular}

Note:

$f e d-h s$ father's education at highschool.

fed - hs - above father's education higher than highschool.

med - hs mother's education at highschool.

med - hs - above mother's education higher than highschool.

secgen second-generation immigrant dummy.

*** significant at $1 \%$ level; ${ }^{* *}$ significant at $5 \%$ level; ${ }^{*}$ significant at $10 \%$ level 
Table 7

\section{Simulated Educational Attainment: Means of Years of Schooling}

\begin{tabular}{|c|c|c|c|c|}
\hline \multirow[b]{2}{*}{ Accumulated Years of Education } & \multicolumn{2}{|c|}{ NLSY97 } & \multicolumn{2}{|c|}{ YITS } \\
\hline & Secgen & Native & Secgen & Native \\
\hline \multicolumn{5}{|c|}{$\begin{array}{l}\text { Simulation } 1^{*} \\
\text { increase those father's education below highschool to highschool graduate, } \\
\text { and praental income is increased accordingly. }\end{array}$} \\
\hline Control & 12.973 & 12.532 & 13.363 & 13.464 \\
\hline Treatment & 12.973 & 12.553 & 13.363 & 13.480 \\
\hline$\%$ Changes & 0 & 0.17 & 0 & 0.15 \\
\hline \multicolumn{5}{|c|}{$\begin{array}{l}\text { Simulation } 2^{* *} \\
\text { increase those mother's education below highschool to highschool graduate, } \\
\text { and praental income is increased accordingly. }\end{array}$} \\
\hline Control & 12.973 & 12.532 & 13.363 & 13.464 \\
\hline Treatment & 12.973 & 12.573 & 13.413 & 13.487 \\
\hline$\%$ Changes & 0 & 0.33 & 0.37 & 0.17 \\
\hline \multicolumn{5}{|c|}{$\begin{array}{l}\text { Simulation } 3^{* * *} \\
\text { increase those parental education below highschool to higher school graduate } \\
\text { and praental income is increased accordingly. }\end{array}$} \\
\hline Control & 12.973 & 12.532 & 13.363 & 13.464 \\
\hline Treatment & 12.973 & 12.603 & 13.41 & 13.50 \\
\hline$\%$ Changes & 0 & 0.57 & 0.37 & 0.30 \\
\hline \multicolumn{5}{|c|}{$\begin{array}{l}\text { Simulation } 4^{* * * *} \\
\text { increase those parental education below or equivalent to highschool } \\
\text { to above highschool, and parental income is increased accordingly. }\end{array}$} \\
\hline Control & 12.973 & 12.532 & 13.363 & 13.464 \\
\hline Treatment & 13.253 & 12.680 & 13.60 & 13.64 \\
\hline$\%$ Changes & 2.16 & 1.18 & 1.8 & 1.5 \\
\hline
\end{tabular}


Table 8

Grade Distributions (in persentage): Control Group

\begin{tabular}{lcc|cc} 
& \multicolumn{2}{c}{ NLSY97 } & \multicolumn{2}{c}{ YITS } \\
Grade Levels & Secgen & Natives & Secgen & Natives \\
\hline 6 & 0 & 0 & 0 & 0 \\
7 & 0 & 0.39 & 0 & 0 \\
8 & 0 & 2.12 & 0 & 0 \\
9 & 4.00 & 7.23 & 0.20 & 0.24 \\
10 & 10.67 & 6.28 & 3.34 & 3.98 \\
11 & 4.00 & 8.09 & 15.32 & 13.86 \\
12 & 42.67 & 42.97 & 32.61 & 32.64 \\
13 & 8.00 & 8.48 & 14.54 & 13.15 \\
14 & 6.67 & 3.93 & 6.09 & 5.87 \\
15 & 4.00 & 3.53 & 7.66 & 6.54 \\
16 & 12.00 & 10.60 & 7.66 & 8.36 \\
17 & 2.67 & 4.24 & 5.30 & 7.30 \\
18 & 1.33 & 1.02 & 1.77 & 3.01 \\
19 & 1.33 & 0.24 & 2.55 & 4.07 \\
20 & 1.33 & 0.16 & 2.95 & 0.99 \\
21 & 1.33 & 0.71 & 0 & 0 \\
22 & 0 & 0 & 0 & 0 \\
\multicolumn{4}{c}{ Mean Accumulated Education } \\
Note: The grade distributions are derived from 2-Types Model \\
\hline \multicolumn{5}{l}{} \\
\hline
\end{tabular}


Table 9

Grade Distributions in \%: Simulation 1

\begin{tabular}{lcc|cc} 
& \multicolumn{2}{c}{ NLSY7 } & \multicolumn{2}{c}{ YITS } \\
Grade Levels & Secgen & Natives & Secgen & Natives \\
\hline 6 & 0 & 0 & 0 & 0 \\
7 & 0 & 0.39 & 0 & 0 \\
8 & 0 & 2.04 & 0 & 0 \\
9 & 4.00 & 7.07 & 0.20 & 0.24 \\
10 & 10.67 & 6.28 & 3.34 & 3.93 \\
11 & 4.00 & 8.01 & 15.32 & 13.78 \\
12 & 42.67 & 42.97 & 32.61 & 32.52 \\
13 & 8.00 & 8.41 & 14.54 & 13.10 \\
14 & 6.67 & 4.01 & 6.09 & 5.83 \\
15 & 4.00 & 3.61 & 7.66 & 6.61 \\
16 & 12.00 & 10.84 & 7.66 & 8.41 \\
17 & 2.67 & 4.24 & 5.30 & 7.39 \\
18 & 1.33 & 1.02 & 1.77 & 2.98 \\
19 & 1.33 & 0.24 & 2.55 & 4.17 \\
20 & 1.33 & 0.16 & 2.95 & 1.04 \\
21 & 1.33 & 0.71 & 0 & 0 \\
22 & 0 & 0 & 0 & 0 \\
\hline Note: The grade distributions are &
\end{tabular}


Table 10

Grade Distributions in \%: Simulation 2

\begin{tabular}{lcc|cc} 
& \multicolumn{2}{c}{ NLSY7 } & \multicolumn{2}{c}{ YITS } \\
Grade Levels & Secgen & Natives & Secgen & Natives \\
\hline 6 & 0 & 0 & 0 & 0 \\
7 & 0 & 0.39 & 0 & 0 \\
8 & 0 & 2.12 & 0 & 0 \\
9 & 4.00 & 6.68 & 0.20 & 0.24 \\
10 & 10.67 & 6.28 & 3.34 & 3.88 \\
11 & 4.00 & 7.86 & 15.13 & 13.83 \\
12 & 42.67 & 43.28 & 32.47 & 32.47 \\
13 & 8.00 & 8.33 & 14.15 & 13.05 \\
14 & 6.67 & 4.01 & 5.89 & 5.87 \\
15 & 4.00 & 3.61 & 7.86 & 6.54 \\
16 & 12.00 & 10.92 & 7.47 & 8.36 \\
17 & 2.67 & 4.40 & 5.89 & 7.53 \\
18 & 1.33 & 1.02 & 1.96 & 3.03 \\
19 & 1.33 & 0.24 & 2.55 & 4.17 \\
20 & 1.33 & 0.16 & 3.14 & 1.02 \\
21 & 1.33 & 0.71 & 0 & 0 \\
22 & 0 & & 0 & 0 \\
\hline Note: The grade distributions are derived from 2-Type Model
\end{tabular}


Table 11

Grade Distributions in \%: Simulation 3

\begin{tabular}{lcc|cc} 
& \multicolumn{2}{c}{ NLSY7 } & \multicolumn{2}{c}{ YITS } \\
Grade Levels & Secgen & Natives & Secgen & Natives \\
\hline 6 & 0 & 0 & 0 & 0 \\
7 & 0 & 0.39 & 0 & 0 \\
8 & 0 & 2.04 & 0 & 0 \\
9 & 4.00 & 6.44 & 0.20 & 0.24 \\
10 & 10.67 & 6.21 & 3.34 & 3.79 \\
11 & 4.00 & 7.62 & 15.13 & 13.74 \\
12 & 42.67 & 43.36 & 32.42 & 32.47 \\
13 & 8.00 & 8.48 & 14.15 & 12.98 \\
14 & 6.67 & 4.01 & 5.89 & 5.83 \\
15 & 4.00 & 3.77 & 7.86 & 6.63 \\
16 & 12.00 & 11.15 & 7.47 & 8.46 \\
17 & 2.67 & 4.40 & 5.89 & 7.56 \\
18 & 1.33 & 1.02 & 1.96 & 3.06 \\
19 & 1.33 & 0.24 & 2.55 & 4.17 \\
20 & 1.33 & 0.16 & 3.14 & 1.09 \\
21 & 1.33 & 0.71 & 0 & 0 \\
22 & 0 & 0 & 0 & 0 \\
\hline Note: The grade distributions are &
\end{tabular}


Table 12

Grade Distributions in \%: Simulation 4

\begin{tabular}{lcc|cc} 
& \multicolumn{2}{c}{ NLSY7 } & \multicolumn{2}{c}{ YITS } \\
Grade Levels & Secgen & Natives & Secgen & Natives \\
\hline 6 & 0 & 0 & 0 & 0 \\
7 & 0 & 0.39 & 0 & 0 \\
8 & 0 & 1.81 & 0 & 0 \\
9 & 4.00 & 5.97 & 0.20 & 0.21 \\
10 & 4.00 & 5.73 & 2.55 & 3.48 \\
11 & 4.00 & 7.70 & 14.15 & 13.07 \\
12 & 45.33 & 42.58 & 30.65 & 31.55 \\
13 & 6.67 & 9.19 & 14.73 & 12.77 \\
14 & 9.33 & 3.93 & 5.89 & 5.80 \\
15 & 2.67 & 4.71 & 7.47 & 6.58 \\
16 & 14.67 & 11.55 & 8.45 & 8.83 \\
17 & 4.00 & 4.32 & 7.47 & 8.03 \\
18 & 2.67 & 1.10 & 2.16 & 3.51 \\
19 & 1.33 & 0.16 & 3.14 & 4.81 \\
20 & 0 & 0.16 & 3.14 & 1.35 \\
21 & 1.33 & 0.71 & 0 & 0 \\
22 & 0 & 0 & 0 & 0 \\
\hline Note: The grade distributions are &
\end{tabular}


Table 13.1

Educational Subsidies: High School Drop-outs

\begin{tabular}{|c|c|c|c|c|}
\hline \multirow[b]{2}{*}{ Annual Dollar Amount Subsidies } & \multicolumn{2}{|c|}{ NLSY97 } & \multicolumn{2}{|r|}{ YITS } \\
\hline & $\mathrm{N}$ & Mean & $\mathrm{N}$ & Mean \\
\hline \multicolumn{5}{|c|}{ Children of Immigrants } \\
\hline High School Total & 14 & $5286 \mathrm{US} \$$ & 96 & $2389 \mathrm{US} \$$ \\
\hline Grade 10 & 7 & $1662 \mathrm{US} \$$ & 6 & $238 \mathrm{US} \$$ \\
\hline Grade 11 & 14 & $2116 \mathrm{US} \$$ & 57 & $565 \mathrm{US} \$$ \\
\hline Grade 12 & 14 & $2339 \mathrm{US} \$$ & 96 & $2038 \mathrm{US} \$$ \\
\hline & \multicolumn{2}{|c|}{ NLSY97 } & \multicolumn{2}{|r|}{ YITS } \\
\hline Annual Dollar Amount Subsidies & $\mathrm{N}$ & Mean & $\mathrm{N}$ & Mean \\
\hline \multicolumn{5}{|c|}{ Children of Natives } \\
\hline High School Total & 307 & $5700 \mathrm{US} \$$ & 763 & $2566 \mathrm{US} \$$ \\
\hline Grade 10 & 222 & $2304 \mathrm{US} \$$ & 70 & $296 \mathrm{US} \$$ \\
\hline Grade 11 & 301 & $1569 \mathrm{US} \$$ & 504 & $741 \mathrm{US} \$$ \\
\hline Grade 12 & 307 & $1894 \mathrm{US} \$$ & 763 & 2041 US\$ \\
\hline
\end{tabular}

Note:

The implied policy targeted on individuals with simulated completed grade less than 12, "High School Total" means average total subsidy amount for each individual to complete high school. "Grade 10", "Grade 11" and "Grade 11" denote grade specific average subsidy for a typical individual to finish a specific grade.

$1 \mathrm{US} \$=1.45 \mathrm{CA} \$$ in 2000 . Not PPP adjusted. 
Table 13.2

Educational Subsidies: High School Graduates but No University

\begin{tabular}{|c|c|c|c|c|}
\hline \multirow[b]{2}{*}{ Annual Dollar Amount Subsidies } & \multicolumn{2}{|c|}{ NLSY97 } & \multicolumn{2}{|c|}{ YITS } \\
\hline & $\mathrm{N}$ & Mean & $\mathrm{N}$ & Mean \\
\hline \multicolumn{5}{|c|}{ Children of Immigrants } \\
\hline University Total & 46 & $9248 \mathrm{US} \$$ & 310 & $4250 \mathrm{US} \$$ \\
\hline Grade 13 & 46 & 5259 US\$ & 310 & $1827 \mathrm{US} \$$ \\
\hline Grade 14 & 46 & $2245 \mathrm{US} \$$ & 310 & $1139 \mathrm{US} \$$ \\
\hline Grade 15 & 46 & $995 \mathrm{US} \$$ & 310 & $652 \mathrm{US} \$$ \\
\hline Grade 16 & 46 & $749 \mathrm{US} \$$ & 310 & $631 \mathrm{US} \$$ \\
\hline & \multicolumn{2}{|c|}{ NLSY97 } & \multicolumn{2}{|c|}{ YITS } \\
\hline Annual Dollar Amount Subsidies & $\mathrm{N}$ & Mean & $\mathrm{N}$ & Mean \\
\hline \multicolumn{5}{|c|}{ Children of Natives } \\
\hline University Total & 750 & 9037 US\$ & 2457 & $4479 \mathrm{US} \$$ \\
\hline Grade 13 & 750 & $4847 \mathrm{US} \$$ & 2457 & $1890 \mathrm{US} \$$ \\
\hline Grade 14 & 750 & 1594 US\$ & 2457 & $1034 \mathrm{US} \$$ \\
\hline Grade 15 & 750 & 1135 US\$ & 2457 & $668 \mathrm{US} \$$ \\
\hline Grade 16 & 750 & $1461 \mathrm{US} \$$ & 2457 & 886 US\$ \\
\hline
\end{tabular}

Note:

The implied policy targeted on individuals with simulated completed grade higher than 12 but lower than 16 .

"University Total" means average total subsidy amount for each individual to complete university. "Grade 13", "Grade 14", "Grade 15", "Grade 16", denote grade specific average subsidy for a typical individual to finish a specific grade.

$1 \mathrm{US} \$=1.45 \mathrm{CA} \$$ in 2000 . Not PPP adjusted. 
Table 14

OLS Regression Results: Test Scores on Initial Education $S_{i 0}$

\begin{tabular}{|c|c|c|c|c|c|c|}
\hline \multirow[b]{2}{*}{ Parameters } & \multicolumn{3}{|c|}{ NLSY97 $(A S V A B-V)$} & \multicolumn{3}{|c|}{ YITS $(P I S A-V)$} \\
\hline & Estimates & Std Err & T-Stat & Estimates & Std Err & T-Stat \\
\hline Intercept & $10.99^{*}$ & 5.68 & 1.94 & $3.95^{* * *}$ & 0.28 & 14.06 \\
\hline Secgen & $71.52^{* * *}$ & 25.25 & 2.83 & $-3.48^{* * *}$ & 0.87 & -4.01 \\
\hline Secgen - Grd & $-6.09^{* *}$ & 2.47 & -2.46 & $0.35^{* * *}$ & 0.09 & 4.03 \\
\hline$S_{i 0}$ & $4.61^{* * *}$ & 0.56 & 8.22 & $0.11^{* * *}$ & 0.03 & 4.03 \\
\hline adjusted $R^{2}$ & & 0.0527 & & & 0.0069 & \\
\hline F-Stats & & 25.99 & & & 11.99 & \\
\hline Dependent Mean (Test Scores) & & 57.79 & & & 5.08 & \\
\hline
\end{tabular}

NOTE :

Secgen: second-generation immigrant dummy.

PISA - V: PISAverbal test score.

$A S V A B-V:$ ASVAB verbal score.

$S_{i 0}$ : initial educational attainment upon age 16 .

Secgen - Grd: Interaction term between Secgen dummy and initial schooling

*** significant at $1 \%$ level; ${ }^{* *}$ significant at $5 \%$ level; ${ }^{*}$ significant at $10 \%$ level 